\title{
Variant Selection During Cooling after Beta Annealing of Ti-6Al-4V Ingot Material
}

\author{
G.A. SARGENT, K.T. KINSEL, A.L. PILCHAK, A.A. SALEM, and S.L. SEMIATIN
}

The selection of alpha variants during the cooling of Ti-6Al-4V from the beta-phase field was investigated. For this purpose, samples with a coarse, columnar beta-grain structure with a $\langle 100\rangle$ fiber texture were extracted from an as-cast production-scale ingot. The alpha variants in the as-cast samples as well as those produced during several successive beta-annealing treatments were determined using electron backscatter diffraction (EBSD). The EBSD results indicated that a subset of the 12 possible variants was developed within each grain; the specific variants were a function of the cooling rate after beta heat treatment. Moreover, the generation of similar variants during successive heat treatments involving an identical cooling rate suggested a noticeable memory effect. The variant selection process was rationalized based on calculations of the strain associated with the beta-to-alpha transformation. These calculations revealed that the overall aggregate strain approached zero in both the as-cast condition as well as after beta heat treatment, suggesting the occurrence of a long-range self-accommodation mechanism.

DOI: $10.1007 / \mathrm{s} 11661-012-1245-\mathrm{y}$

(C) The Minerals, Metals \& Materials Society and ASM International 2012

\section{INTRODUCTION}

THE influence of crystallographic texture on mechanical properties can be especially strong in polycrystalline metallic materials whose crystal structures exhibit low symmetry, such as those based on a hexagonal close-packed (hcp) phase. For titanium and its alloys, for example, both first-tier properties such as yield strength and ductility and second-tier properties such as fracture toughness and fatigue response are affected. ${ }^{[1-3]}$

Texture in titanium alloys may be developed as a result of deformation, dynamic/static recrystallization, grain growth, or phase transformation. ${ }^{[4,5]}$ To date, a large amount of research has been conducted to understand the development of deformation textures due to processes such as sheet rolling, extrusion, and forging. For the workhorse titanium alloy Ti-6Al-4V, which contains a large proportion of the hep alpha phase and a small amount of body-centered cubic (bcc) beta phase, the deformation mode and processing temperature have a strong influence on texture. ${ }^{[6,7]}$ Less work has been performed to understand texture evolution due to recrystallization, grain growth, and phase

G.A. SARGENT, Consultant, is with UES, Inc., Wright Patterson Air Force Base, OH 45433. Contact e-mail: Gordon.Sargent.ctr@ wpafb.af.mil K.T. KINSEL, Research Student, is with the Mechanical Engineering Department, Wright-State University, Dayton, $\mathrm{OH}$ 45435. A.L. PILCHAK, Materials Research Engineer, is with the Air Force Research Laboratory, Materials and Manufacturing Directorate, AFRL/RXLM, Wright-Patterson Air Force Base, OH. A.A. SALEM, CEO, is with Materials Resources LLC, Dayton, OH 45434. S.L. SEMIATIN, Senior Scientist, is with the Air Force Research Laboratory, Materials and Manufacturing Directorate, AFRL/RXLM, Wright-Patterson Air Force Base.

Manuscript submitted January 23, 2012.

Article published online June 27, 2012 transformation. Recrystallization and grain growth in single-phase alpha and single-phase beta titanium have been found to be controlled generally by nucleation- and growth-type processes. Among other factors, the starting texture, the nature of stored energy, and the anisotropy of boundary energy and mobility each affect the evolution of such types of textures. ${ }^{[8-11]}$

Transformation textures in titanium alloys arise from the decomposition of the high temperature, metastablebeta phase to produce alpha lamellae/laths within a beta matrix. The transformation follows a classic Burgers relationship ${ }^{[12]}$ such that the respective closed-packed planes and directions of the parent beta and product alpha phases are parallel to each other; i.e., $\{110\}_{\beta} \|(0001)_{\alpha}$ and $\langle 1 \overline{1} \overline{1}\rangle_{\beta} \|\langle 2 \overline{1} \overline{1} 0\rangle_{\alpha}$. Because there are six $\{110\}$-type planes and two $\langle 111\rangle$-type directions on each of these planes in a bcc crystal, 12 distinct alpha variants may be developed within each beta grain of a polycrystalline aggregate. If all 12 variants were to form within each beta grain, the transformation texture would be relatively weak. However, typically only a small subset of the possible variants is formed within each grain, leading to overall textures of various strengths.

The literature on titanium alloys reveals a number of interesting phenomena related to variant selection. Weak to relatively strong alpha-phase textures have been observed in Ti-6Al-4V, which has been annealed in the single-phase beta field. ${ }^{[13,14]}$ Relatively strong alphaphase textures caused by beta transformation have been observed in Ti-6Al-4V, which has been hot worked in the beta field prior to cooling ${ }^{[15]}$ or rapidly cooled after annealing in the two-phase (alpha + beta) field. ${ }^{[13]}$ In the former instance, the selected variants tended to correlate with the beta slip systems that had been most active during the prior deformation. ${ }^{[16]}$ With regard to 
decomposition of the beta phase after annealing in the two-phase field, it has been hypothesized that local stresses develop during cooling as a result of differences in coefficients of thermal expansion of the two phases; these stresses tend to favor the formation of alpha variants whose orientations are similar to those of the primary alpha. ${ }^{[17]}$ In related work, ${ }^{[18]}$ the biasing of the texture of the transformation product (i.e., the secondary alpha) by that of the primary alpha was modeled based on a minimum strain-energy hypothesis and gave good predictions of observed textures. In yet other research, Zeng and Bieler ${ }^{[19]}$ postulated that the anisotropic thermal contraction of primary alpha during cooling may activate slip on selected $\{110\}$ slip planes in the beta phase, thus biasing the secondary-alpha variants that are formed.

Several other characteristics have been noted with regard to variant selection during cooling after beta annealing of titanium alloys. These concern variant nucleation rules based on certain crystallographic relationships at beta grain boundaries and a so-called "memory" effect. With regard to the first phenomenon, several research efforts have shown that preferential nucleation of alpha variants at beta grain boundaries occurs on nearly parallel $\{110\}_{\beta}$ planes in the two grains, thus leading to nearly parallel $[0001]_{\alpha}$ directions in the variants on either side of the grain boundary. ${ }^{[20,21]}$ This suggests that each variant at a grain boundary should satisfy the Burgers relation with the beta phase of the grain in which it lies as well as with the adjacent grain in at least an approximate sense. This criterion has also been found to be important for the ferrite-to-austenite transformation in microalloyed steels. ${ }^{[2]}$ This recent work on microalloyed steels has also indicated the importance of another factor, namely, the fact that a variant is favored if its close-packed plane is parallel to a segment of parent grain boundary containing a corresponding close-packed plane.

The importance of crystallography at parent grain boundaries in influencing variant selection provides insight into the memory effect, i.e., the reappearance of specific product-phase texture components during repeated heating and cooling cycles through the transformation temperature regime. The phenomenon has been noted in Ti-6Al-4 $\mathrm{V}^{[23]}$ and commercial-purity titanium $^{[24]}$ for cases involving complete dissolution of the low-temperature phase prior to cooling. A similar memory effect has also been found for Ti-6Al-4V, ${ }^{[24]}$ Zircaloy-2, ${ }^{[25]}$ and $\mathrm{Zr}-2.5 \mathrm{Nb}^{[26]}$ when the peak temperature during the heat-treatment cycle results in the retention of some primary low-temperature phase; these observations, however, may be ascribed to biasing stresses developed during cooling as a result of differences in coefficients of thermal expansion of the two phases as noted.

Because most previous investigations of variant selection in titanium alloys have used fine-grain polycrystalline materials, observations and conclusions have largely been based on statistical averages such as pole figures and/or orientation-distribution functions (ODFs). The objective of the current investigation, therefore, was to develop insight into variant selection on a local, grain- by-grain basis. For this purpose, the alpha variants developed during repeated beta annealing and cooling of coarse-grain samples extracted from a production-scale ingot were determined and used to estimate the degree of memory effect. Such coarse-grain samples minimized the amount of beta grain growth (and hence, changes in the grain-boundary geometry) during transients into the single-phase field. In addition, insight into rules that may underlie the selection of the volume fractions of the variants was obtained by calculations of the local transformation strains.

\section{MATERIAL AND PROCEDURES}

\section{A. Material}

A Ti-6Al-4V ingot with $915 \mathrm{~mm}$ diameter, $1700 \mathrm{~mm}$ height produced by RTI (formerly RMI Titanium, Niles, $\mathrm{OH}$ ) was used to investigate variant selection and the memory effect in a coarse-grain material with a relatively stable beta grain size. This ingot was the same material used in a previous research investigation. ${ }^{[27]}$ The measured composition in weight percent, at the location at which samples were extracted for the current effort, was 6.15 aluminum, 3.98 vanadium, 0.206 oxygen, 0.20 iron, 0.0076 nitrogen, 0.0268 carbon, and 0.0019 hydrogen, with the balance being titanium. The ingot had been synthesized by vacuum arc remelting of a $760 \mathrm{~mm}$ diameter electrode into a water-cooled copper crucible. During melting, the current and voltage had been maintained at a fixed level resulting in a melt rate of approximately $130 \mathrm{~kg} / \mathrm{min}$. A 5-gauss magnetic field that reversed its direction every 60 seconds was used to induce stirring of the melt. Unlike typical production practice, however, the melting process was terminated at full power without a hot-topping procedure, which would have ensured that the upper portion of the ingot would have solidified uniformly. Thus, there was considerable shrinkage porosity in the top third of the ingot.

After melting and solidification, the ingot was cut diametrically along its entire length, and a 50.8- $\mathrm{mm}$ thick axial plate was sectioned from one of the two halves. In turn, this plate was cut into six separate pieces annotated 1T, 2T, 1M, 2M, 1B, and 2B (Figure 1). The bottom, right-hand piece (2B), which was free of porosity and had likely experienced solidification conditions typical of a conventionally melted and hottopped ingot, was chosen for the current work. Piece $2 \mathrm{~B}$ was sectioned to produce test samples located at $r / R \sim$ 0.77 and $z / H \sim 0.32$, in which $r, z$, and $\theta$ denote the axes of a cylindrical-coordinate system, and $R$ and $H$ are the outer radius and height of the ingot, respectively (Figure 1). The research reported herein was conducted largely on the sample designated 2B-B-1-1; a few measurements used sample 2B-B-1-2. Each sample had dimensions of $25 \times 25 \times 75 \mathrm{~mm}$.

In the as-cast condition, the macrostructure of the two test samples comprised coarse columnar beta grains with a diameter of $\sim 10 \mathrm{~mm}$, within each of which colonies of alpha lamellae with a thickness of $\sim 4 \mu \mathrm{m}$ were found. 


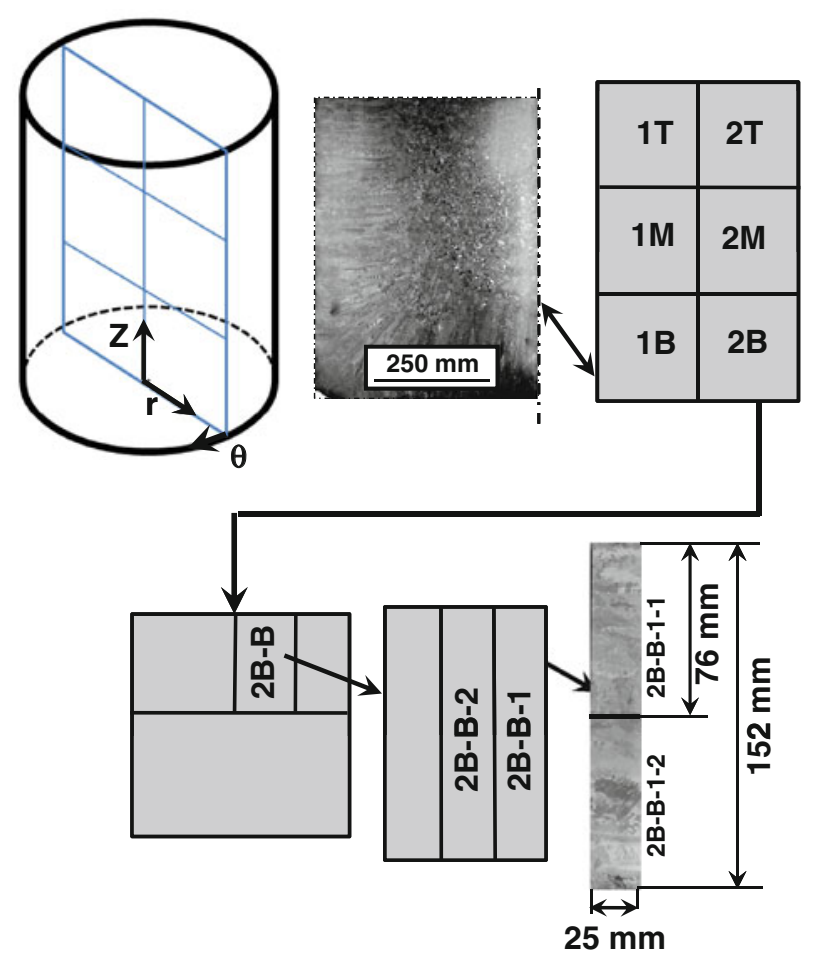

Fig. 1-Schematic illustration of the ingot coordinate system $(r, \theta, z)$, sectioning plan for the Ti-6Al-4V ingot and specific test samples used in the current work.

\section{B. Experimental Procedures}

The microstructure and texture of the test samples were determined in both the as-received (as-cast) condition and after each of a series of five subsequent beta heat treatments, denoted HT1, HT2, HT3, HT4, and HT5. The beta heat treatments were conducted in a vacuum furnace (evacuated to $\leq 10^{-6}$ torr) to minimize contamination by interstitials. Each heat treatment consisted of an initial heat up at a rate of $20 \mathrm{~K} / \mathrm{min}$ $\left(20^{\circ} \mathrm{C} / \mathrm{min}\right)$ to a peak temperature of $1313 \mathrm{~K}\left(1040{ }^{\circ} \mathrm{C}\right)$ $\left[=T_{\beta}+55 \mathrm{~K}\right.$, in which $T_{\beta}$ denotes the beta-transus temperature at which alpha + beta $\rightarrow$ beta]. After a soak period of 30 minutes at the peak temperature, each sample was cooled at either $15 \mathrm{~K} / \mathrm{min}\left(15^{\circ} \mathrm{C} / \mathrm{min}\right)$ (HT1, HT2, and HT5) or $5 \mathrm{~K} / \mathrm{min}\left(5^{\circ} \mathrm{C} / \mathrm{min}\right)(\mathrm{HT} 3$ and HT4). During several heat treatments, a scrap piece of Ti-6Al-4V with a fine, wrought (equiaxed-alpha) microstructure and similar interstitial/iron content was annealed with the test sample to confirm the excursion into the beta-phase field during the heating cycle via an inspection of its final microstructure.

The "center" and "right" faces of the test sample, which contained the $r-z$ and $\theta-z$ planes, respectively (Figure 2), were prepared in the as-received condition and after each heat treatment via grinding, mechanical polishing, and final polishing with noncrystallizing colloidal silica. An additional section parallel to the right face lying at the midthickness plane was also prepared after HT4 to compare free surface and interior/ bulk behaviors. Each grinding operation between heat

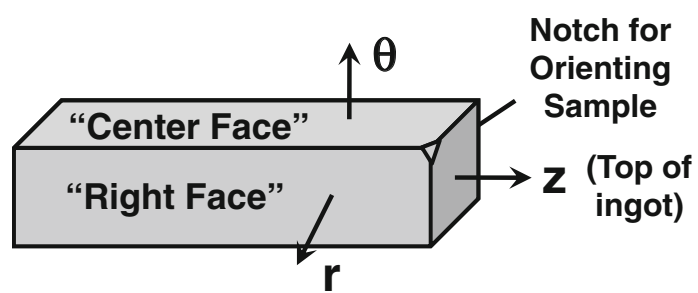

Center Face: $R D=r, T D=z, N D=\theta$
Right Face: $R D=-\theta, T D=z, N D=r$

Fig. 2 - Coordinate system and nomenclature for the test-sample faces on which texture measurements were made. RD, TD, and $\mathrm{ND}$ are the EBSD-coordinate-system axes whereas $r, \theta$, and $z$ are the ingot-coordinate-system axes.

treatments removed a $\sim 0.2-\mathrm{mm}$-thick layer from each of the two faces.

After polishing, each sample was mounted in a custom-made, adjustable holder and aligned parallel with the $x-y$ plane of the stage of an XL30 field-emission gun scanning electron microscope (FEG-SEM) manufactured by FEI Corporation (Hillsboro, OR). The microscope was operated at $20 \mathrm{kV}$ with a final aperture diameter of $100 \mu \mathrm{m}$, thereby producing a probe current of approximately $10 \mathrm{nA}$. The stage was tilted $70 \mathrm{deg}$ for all measurements. Local alpha-phase Kikuchi patterns produced as a result of electron backscatter diffraction (EBSD) were collected over the entire sample face at a rate of $\sim 200$ frames per second using a 10 to $15-\mu \mathrm{m}$ step size and were analyzed with EDAX/TSL OIM software (EDAX Corporation, Mahwah, NJ). The large scan area necessitated both beam and stage control. ${ }^{[28]}$ The correspondence between the sample/EBSD reference direction (RD), transverse direction (TD), and normal direction (ND) and the ingot $r, z$, and $\theta$ axes is shown in Figure 2. Because of the limited volume fraction of the beta phase in Ti-6Al-4V at room temperature $(\sim 5 \mathrm{pct})$ and the large step size, reliable EBSD results for this phase could not be obtained directly.

Data reduction consisted of (1) an analysis of the Kikuchi patterns to determine local alpha-phase orientations (using the EDAX OIM software), (2) stitching of the discrete patches of data determined at each position of the sample stage, ${ }^{[29]}$ (3) determination of the underlying beta-grain orientations and beta grain boundaries (using the commercially-available software MRL-TiBor, Materials Resources LLC, Dayton, OH), and (4) binning of the appropriate data points to determine the volume fraction of each alpha variant within a given beta grain or adjacent to a specific beta grain boundary. The MRL-TiBor software uses a method similar to that developed by Humbert et al..$^{[30,31]}$ and Glavicic et al. ${ }^{[32,33]}$ In this code, however, the quaternion parameterization of orientation space is used in conjunction with average alpha colony orientations (as described by Pilchak and Williams ${ }^{[34]}$ ) in contrast to the pixel-by-pixel methods employed by the previous researchers. This enables complete reconstruction of the beta grains in an area measuring $\sim 25 \mathrm{~mm} \times 40 \mathrm{~mm}$ (at 10 to $15 \mu \mathrm{m}$ resolution) in several minutes. 


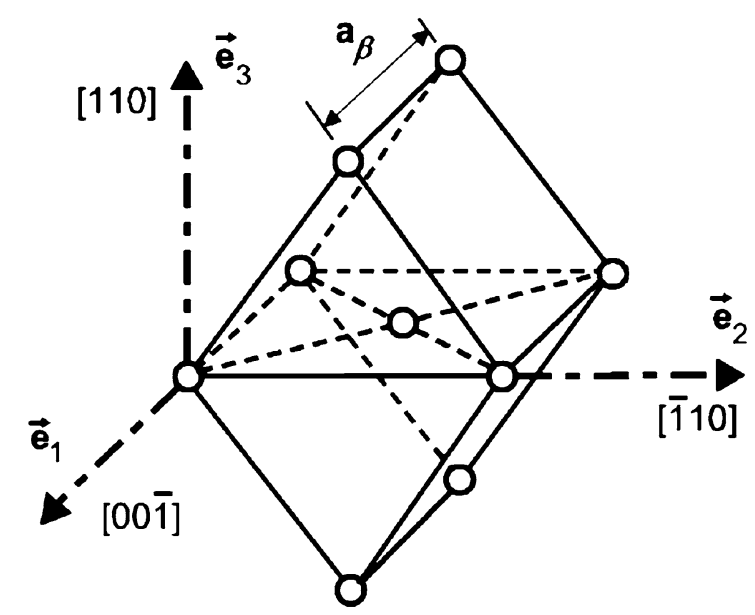

(a)

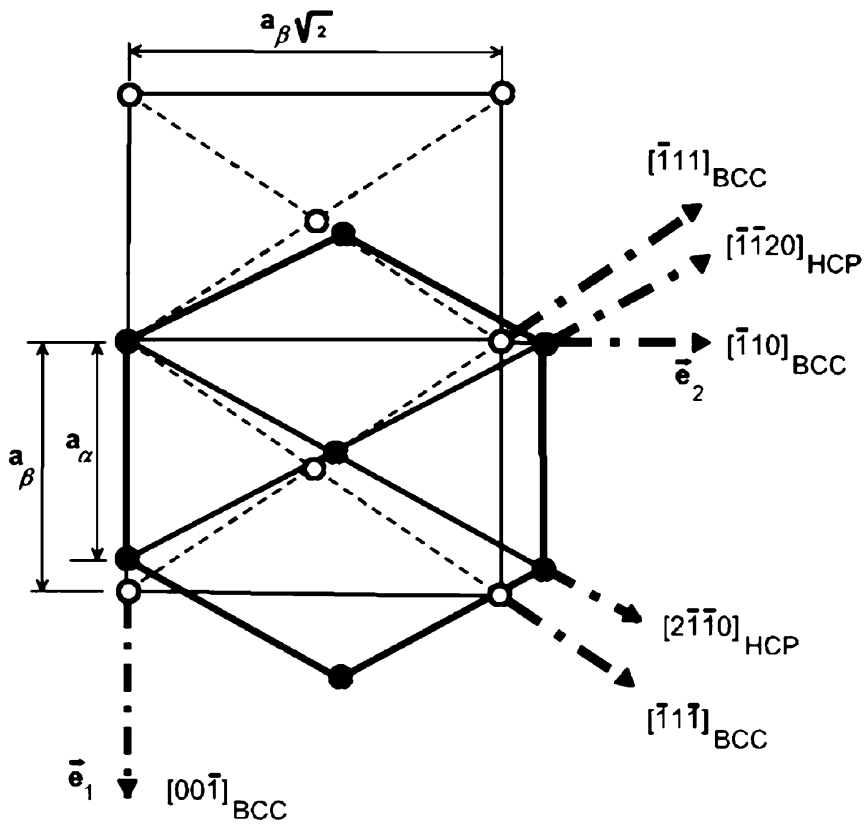

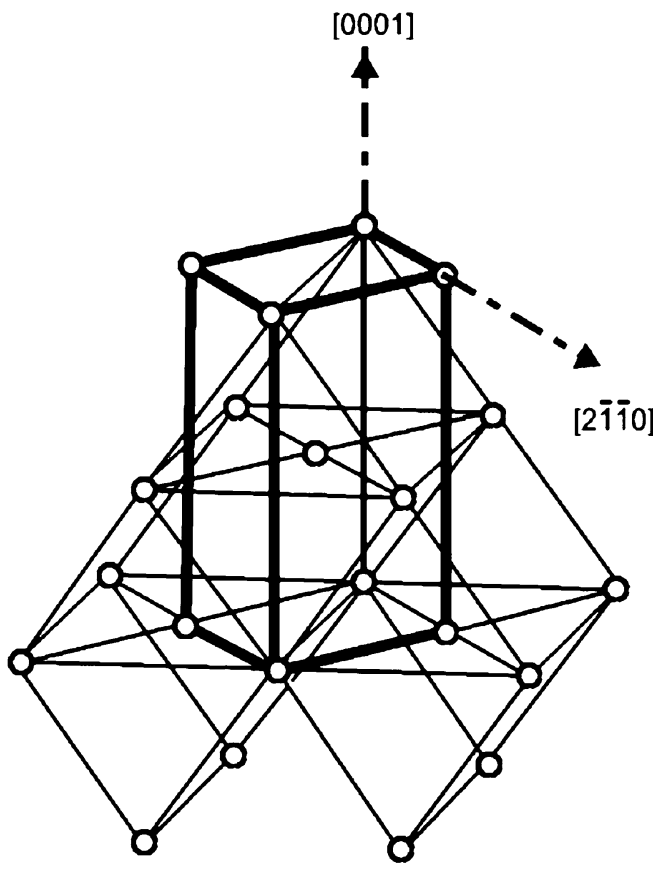

(c)

(b)

Fig. 3-Deformation associated with the transformation of a bcc to an hep crystal: $(a)$ bcc unit cell, (b) distortion in the bcc close-packed plane, and $(c)$ distorted hcp unit cell overlaid onto bcc unit cell. ${ }^{[18,35]}$.

The orientation of each (measured) alpha and (calculated) beta phase point was quantified in terms of Bunge Euler angles ${ }^{[4]}$ and the associated rotation matrix with rotations measured from the ingot/sample $(r, z, \theta)$ axes to the $[2 \overline{1} \overline{1} 0],[01 \overline{1} 0]$, and [0001] axes (alpha phase) or the [100], [010], and [001] cube axes (beta phase).

\section{Modeling Procedures}

Insight into the factors that influence the volume fractions of the variants formed within each beta grain of the Ti-6Al-4V ingot was obtained by determining the strains associated with the beta-to-alpha phase transformation for each of the observed variants in the as-cast and cast-and-beta-annealed conditions. This strain is readily calculated in the beta coordinate system shown in Figure $3 .{ }^{[18,35]}$ Here, the transformation is quantified in terms of three normal strains, two in the $\{110\}_{\beta}$-type plane that distorts to become the $(0001)_{\alpha}$ plane and a third along the corresponding $\langle 110\rangle_{\beta}$ axis, which is normal to this plane and parallel to $[0001]_{\alpha}$. Assuming that small strain theory is applicable, the three normal strains are thus equal to $\left(a_{\alpha} / a_{\beta}\right)-1,((\sqrt{3 / 2})$ $\left.\left(a_{\alpha} / a_{\beta}\right)\right)-1$, and $\left(c_{\alpha} /\left(a_{\beta} \sqrt{2}\right)\right)-1$, in which $a_{\beta}$ and $a_{\alpha}, c_{\alpha}$ denote the corresponding lattice parameters in the beta and alpha phases, respectively (Figure 3). For Ti$6 \mathrm{Al}-4 \mathrm{~V}$, the lattice parameters were taken to be $a_{\beta}=$ $0.331 \mathrm{~nm}, a_{\alpha}=0.295 \mathrm{~nm}$, and $c_{\alpha}=0.468 \mathrm{~nm},{ }^{[36,37]}$ thus yielding the three normal (principal) strains, $\varepsilon_{11}=-0.109$, $\varepsilon_{22}=+0.092$, and $\varepsilon_{33}=0.00$, associated with the 
$\left[\begin{array}{lll}0 & 0 & \overline{1}\end{array}\right],\left[\begin{array}{lll}\overline{1} & 1 & 0\end{array}\right]$, and $\left[\begin{array}{ll}1 & 10\end{array}\right]$ coordinate axes, respectively (Figure 3).

The ingot-coordinate-system strains associated with the formation of each specific alpha variant were calculated using the following steps:
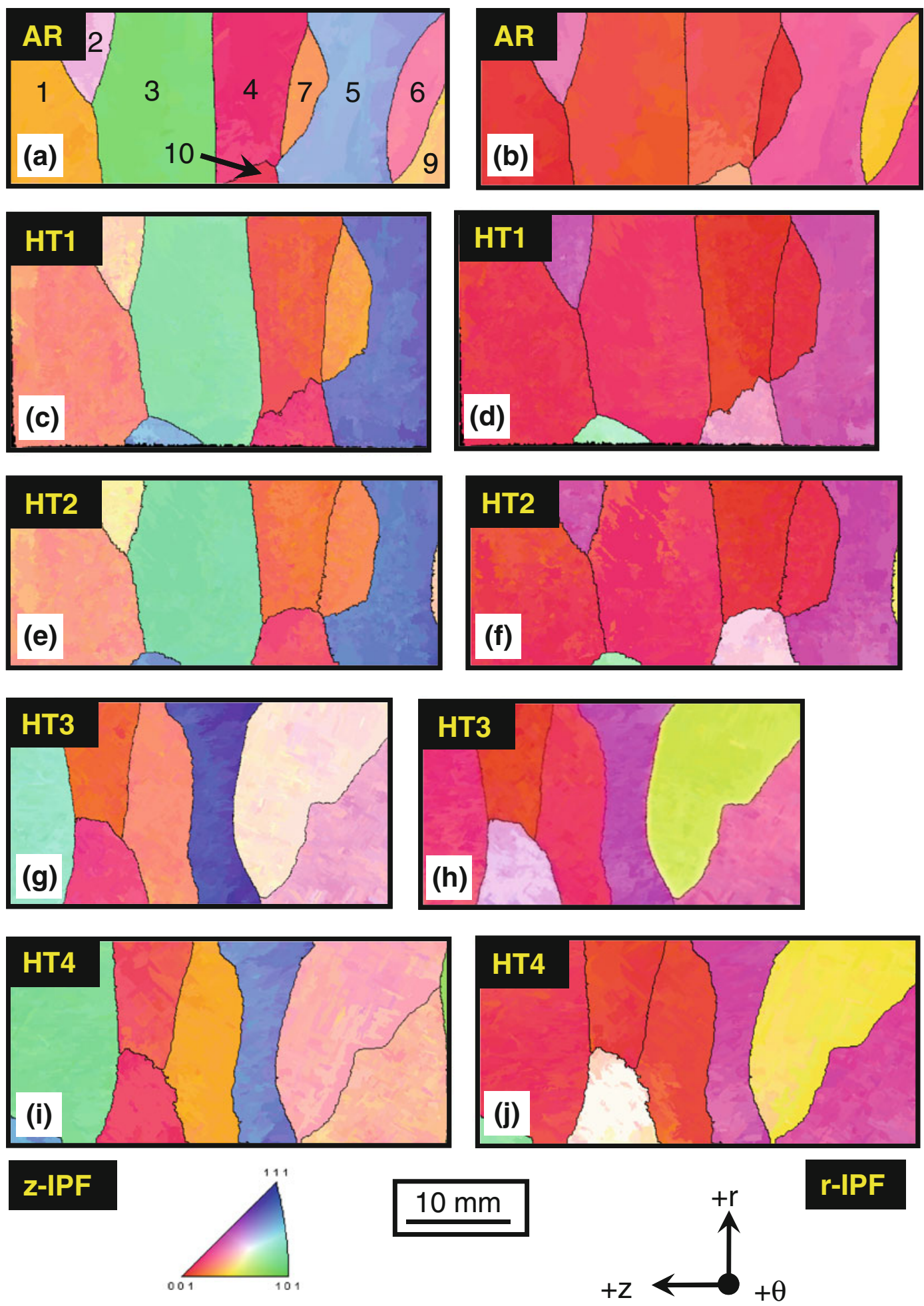

Fig. 4 - Calculated beta-phase inverse-pole-figure maps for $(a, c, e, g, i)$ the $z$-direction and $(b, d, f, h, j)$ the $r$-direction for the center face of sample 2B-B-1-1 in (a and b) the as-received (as-cast) condition and after heat treatment (c and d) HT1, (e and f) HT2, (g and h) HT3, or (i and j) HT4. Center-face beta-grain IDs are indicated in (a). 
variants with the same transformation strain but different rotations required to meet the Burgers criterion concerning close-packed directions.

(b) Using standard tensor algebra, the strains from step (a) were transformed first to the cube-axis system of the beta crystal ([100], [010], [001]) and then to the ingot-coordinate system. The latter straintensor transformation (from the "old" cube axes to the "new" sample axes) made use of the transpose of the rotation (direction cosine) matrix based on the Euler angles $\left(\phi_{1}, \Phi, \phi_{2}\right)$ for the specific beta grain.

(c) The strains in the ingot-coordinate system developed by the formation of a specific (observed) alpha variant were determined by comparing the direction cosines of its basal-plane-normal (in the ingot-coordinate system) to the six different possible sets of direction cosines for the $\{110\}_{\beta}$ planes (in the ingot-coordinate system). The system for which there was coincidence (or near coincidence) of the direction cosines was chosen to be the one controlling the formation of the specific variant. The set of ingot-coordinate-system strains for that system [step (b)] was thus associated with the formation of the specific alpha variant.

\section{RESULTS AND DISCUSSION}

The principal results of this research pertain to (1) the stability of the beta grain structure and the nature of surface $v s$ internal observations, (2) the alpha-variant memory effect, and (3) the influence of transformation strain on the alpha variants that are selected.

\section{A. Beta Grain Structure and Surface/Interior Observations}

The calculated beta grain microstructure of the Ti-6Al-4V ingot material in the as-received (as-cast) condition and after each of the beta-annealing treatments exhibited little change. As exemplified by center-face, beta-phase inverse-pole-figure (IPF) maps reconstructed from alpha-phase EBSD data (Figure 4, Table I), the grain size and grain shape appeared relatively stable even after successive treatments in the high-temperature, single-phase field.

The differences in the IPF maps may be ascribed partially to the thin layers of material removed after each heat treatment. For this reason, EBSD measurements would tend to reveal slightly different sections through the original columnar grain structure. Some of the grains would therefore tend to appear narrower and some wider during successive observations. In addition, the amount of beta grain growth would be expected to be small. An upper bound for such growth can be estimated from phenomenological measurements in the literature for the growth of equiaxed grains in Ti-6Al-4V ${ }^{[38]}$ viz.

$$
\begin{aligned}
d^{2}\left(\mu \mathrm{m}^{2}\right)-d_{\mathrm{o}}^{2}\left(\mu \mathrm{m}^{2}\right)= & 1.11 \times 10^{15} t \\
& \times \exp (-37,500 / T(\mathrm{~K}))
\end{aligned}
$$

Table I. Euler Angles (Deg) and Cube-Axis Rotation for Beta Grains in As-Received Ti-6Al-4V Ingot Sample 2B-B-1-1AR

\begin{tabular}{lrrrrc}
\hline & $\begin{array}{c}\text { Grain } \\
\text { Face }\end{array}$ & \multicolumn{1}{c}{$\phi_{1}$} & \multicolumn{1}{c}{$\Phi$} & \multicolumn{1}{c}{$\phi_{2}$} & $\begin{array}{c}\text { Cube Axis } \\
\text { Rotation (Deg) }{ }^{* \dagger}\end{array}$ \\
\hline Center & 1 & 168.8 & 15.9 & 192.5 & 16 \\
Center & 2 & 206.8 & 27.8 & 136.6 & - \\
Center & 3 & 177.3 & 38.8 & 188.4 & 39 \\
Center & 4 & 159.2 & 7.8 & 192.9 & 9 \\
Center & 5 & 198.0 & 36.1 & 180.8 & - \\
Center & 6 & 4.7 & 9.6 & 13.5 & - \\
Center & 7 & 353.6 & 15.1 & 3.2 & 15 \\
Center & 9 & 329.9 & 24.2 & 37.1 & 23 \\
Center & 10 & 94.5 & 69.8 & 274.4 & - \\
Right & 1 & 327.3 & 17.1 & 37.3 & - \\
Right & 2 & 295.1 & 9.8 & 95.3 & 31 \\
Right & 3 & 91.0 & 3.4 & 261.2 & 8 \\
Right & 4 & 92.5 & 5.18 & 248.4 & 19 \\
Right & 6 & 211.1 & 3.7 & 154.0 & 6 \\
Right & 7 & 300.8 & 8.4 & 79.4 & 21 \\
Right & 8 & 270.1 & 2.8 & 106.3 & 16 \\
Right & 9 & 187.6 & 21.5 & 182.9 & - \\
Right & 10 & 170.2 & 3.2 & 173.9 & 16 \\
Right & 14 & 1.0 & 4.8 & 352.1 & 7 \\
Right & 15 & 183.8 & 21.7 & 141.3 & - \\
Right & 16 & 159.8 & 7.3 & 162.3 & 38 \\
\hline
\end{tabular}

${ }^{*}$ Approximate rotation about $\langle 100\rangle_{\beta}$ fiber axis $(r$ direction) from $\left(\phi_{1}, \Phi, \phi_{2}\right)=(0 \mathrm{deg}, 0 \mathrm{deg}, 0 \mathrm{deg})$.

Cube axis rotation calculated only for grains whose orientation is close to one that could lie within a perfect fiber texture.

in which $d$ and $d_{\mathrm{o}}$ denote the instantaneous and initial grain sizes, and $t$ and $T$ are the heat treatment time (in seconds) and temperature (in K). For a heat treatment at $1040{ }^{\circ} \mathrm{C}(1313 \mathrm{~K})$ lasting 30 minutes (1800 seconds), a microstructure with an initial beta grain diameter of $10^{4} \mu \mathrm{m}(10 \mathrm{~mm})$ would grow by $\sim 39 \mu \mathrm{m}$. Because a columnar grain structure has less surface area per unit volume than an equiaxed structure, the amount of beta grain growth would be less. Thus, four successive betaannealing treatments may be expected to increase the average grain size by $\sim 1$ pct $\left(\sim 100 \mu \mathrm{m} / 10^{4} \mu \mathrm{m}\right)$.

The stability of the beta grain structure was also highlighted in reconstructed right-face, beta-phase IPF maps, such as those shown in Figures 5(a) and (c) for material in the as-received condition and after the fourth heat treatment, respectively. The second of these two IPF maps also bears a close resemblance to that for a parallel internal section taken $\sim 11 \mathrm{~mm}$ from the rightface surface after the fourth heat treatment (Figures 5(c) vs (e)). Such an observation underscores the columnargrain nature of the ingot material. In contrast to the calculated beta phase IPF maps, the corresponding (measured) alpha-phase IPF maps (Figures 5(b), (d), and (f)) did reveal some differences. The difference lay primarily in the variants in the as-received condition $v s$ those after the fourth heat treatment. Each grain in the former condition tended to have fewer and different variants than those noted after the fourth heat treatment (Figure 6). More importantly, the principal variants observed on the right face and the internal plane parallel 

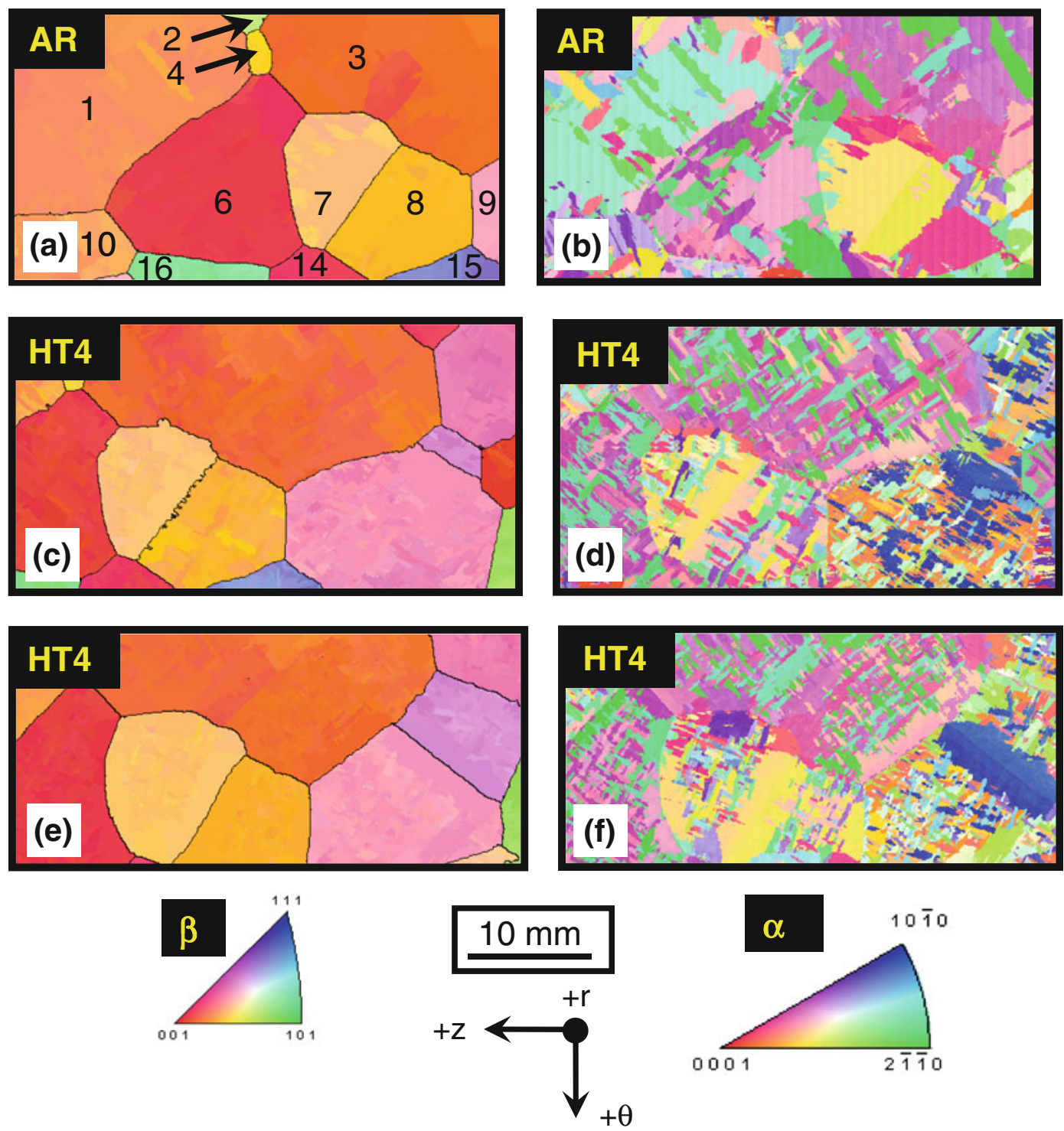

Fig. 5-Z-direction IPF maps for ( $a$ and $c$ ) the calculated beta phase and ( $b$ and $d$ ) the measured alpha phase on the right face of sample 2B-B$1-1$ in the (a and b) as-received (as-cast) condition and (c and d) after heat treatment HT4. ( $e$ and $f$ ) The corresponding IPF maps after heat treatment HT4 for an internal section lying parallel to but $\sim 11 \mathrm{~mm}$ from the right face. Right-face beta-grain IDs are indicated in (a).

to it after the fourth heat treatment were similar (Figures 6(c) and (d) vs (e) and (f)). Hence, the use of surface observations to infer the variants in the bulk is justified at least to a first order.

\section{B. Memory Effect}

The alpha-phase variant-selection data revealed a moderate-to-strong memory effect during successive beta-annealing heat treatments. This effect was dependent on the cooling rate from the beta phase field.

The broad observations are summarized in the alphaphase IPF maps for the center and right faces of sample 2B-B-1-1 in Figure 7. The variants in the as-received (AR) material exhibited a colony microstructure by and large, as evidenced by the solid patches of color. In contrast, each of the heat-treated (HT) conditions showed a Widmanstatten (basketweave) microstructure with some, but not all, the beta grain boundaries decorated by a layer of alpha. The IPF maps also revealed variants that appeared similar for HT1 and HT2 (with a cooling rate of $15 \mathrm{~K} / \mathrm{min}\left(15^{\circ} \mathrm{C} / \mathrm{min}\right)$ after beta heat treatment); the IPFs for HT1 and HT2 also showed some of the same colors/alpha variants as those for the AR sample. The IPF maps for HT3 and HT4, which comprised a cooling rate of $5 \mathrm{~K} / \mathrm{min}\left(5{ }^{\circ} \mathrm{C} / \mathrm{min}\right)$, were similar to each other as well but were noticeably different from those for the AR, HT1, and HT2 observations.

The IPF map observations were quantified in histograms for the alpha-phase variants within each beta grain. The trends taken from the center face for grain 3 (Figure 8) and grain 7 (Figure 9) (which correspond, respectively, to the green and orange grains in the beta phase, $z$-IPF maps in Figure 3) were representative of all the plots. It should be noted that the variant number in these (and other) histograms implies a specific 


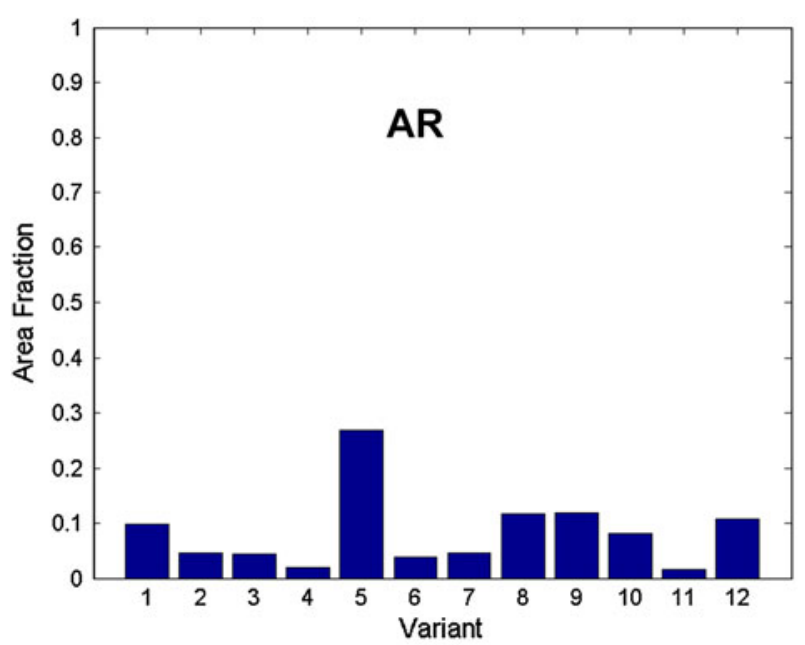

(a)

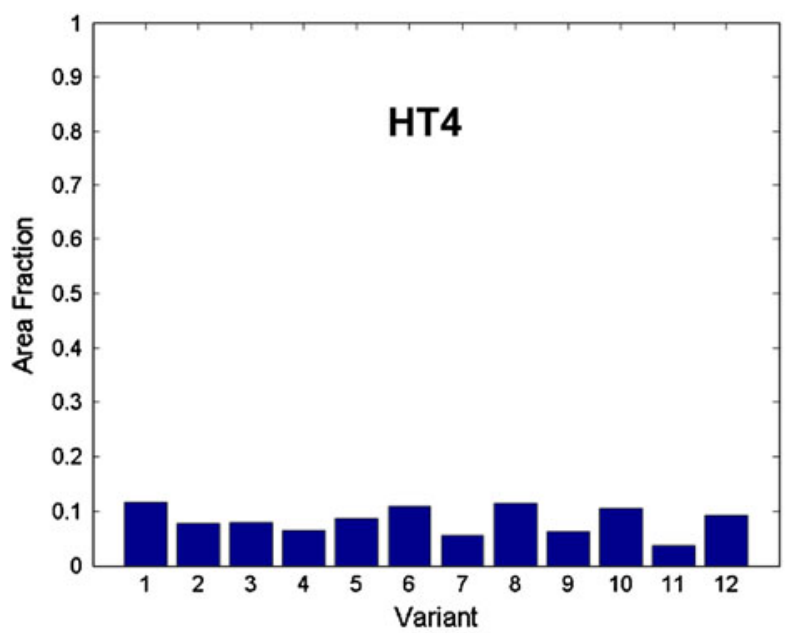

(c)

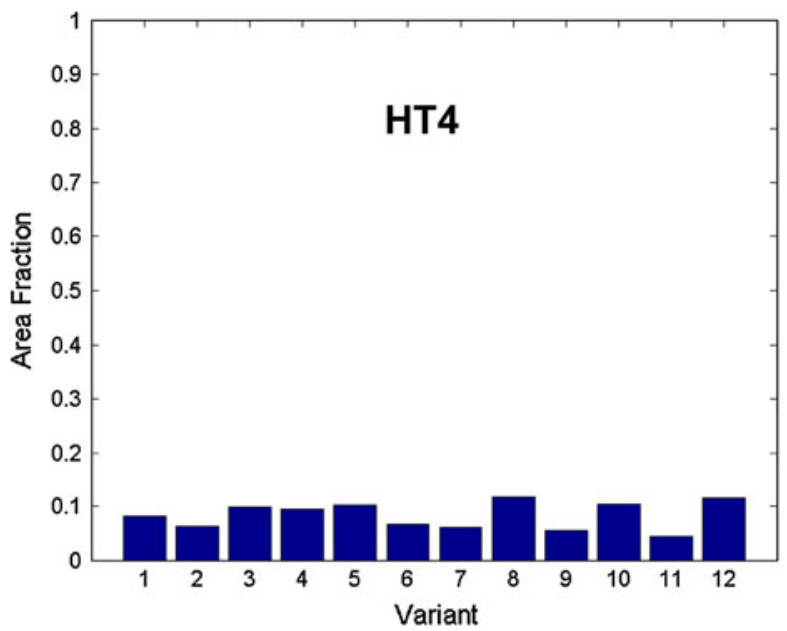

(e)

Grain 3R

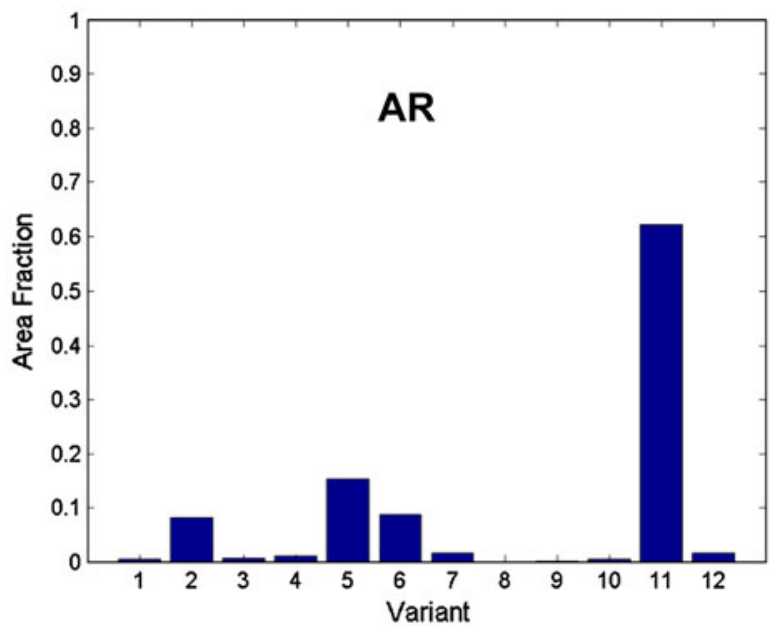

(b)

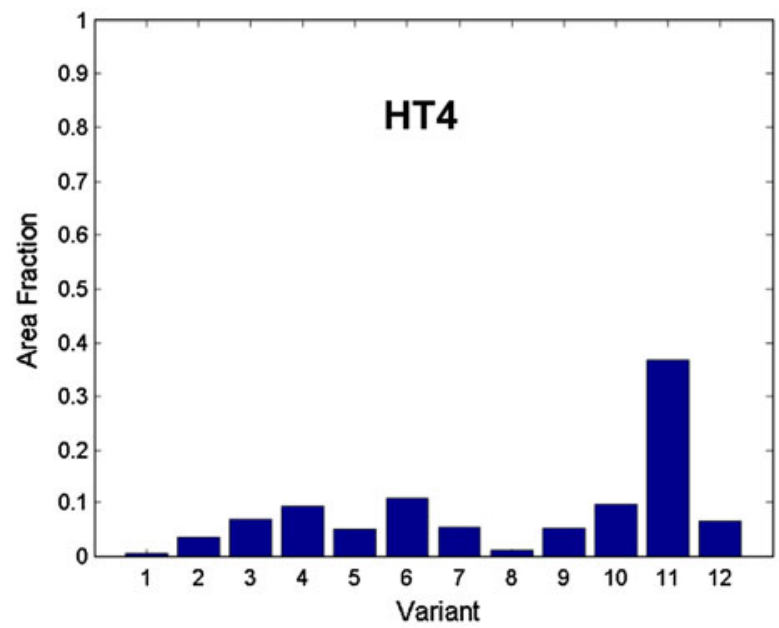

(d)

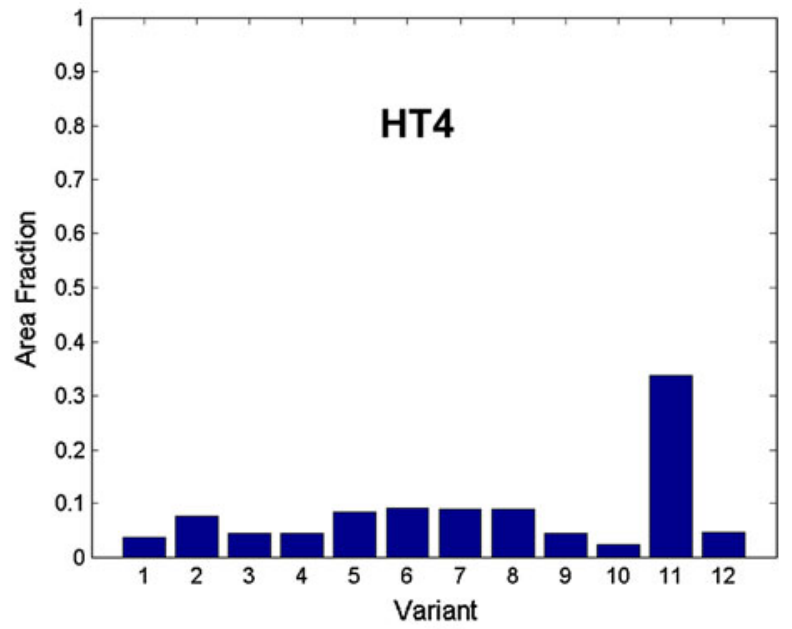

(f)

\section{Grain 7R}

Fig. 6-Histograms showing the area fractions of alpha-phase variants in two different beta grains $(a, b, c$, and $d)$ on the right face or $(e$ and $f$ ) an internal plane parallel to the right face (a and b) in the as-received condition or (c, d, e, and f) after heat treatment HT4 of sample $2 \mathrm{~B}-\mathrm{B}-1-1$.

orientation of a given variant relative to its parent betagrain orientation. Thus, a specific variant number in two different beta grains does not imply a unique orientation relative to the ingot-axis system. In addition, variant pairs comprising consecutive odd and even numbers (e.g., 1 and 2, 3 and 4, 5 and 6, etc.) exhibited the 

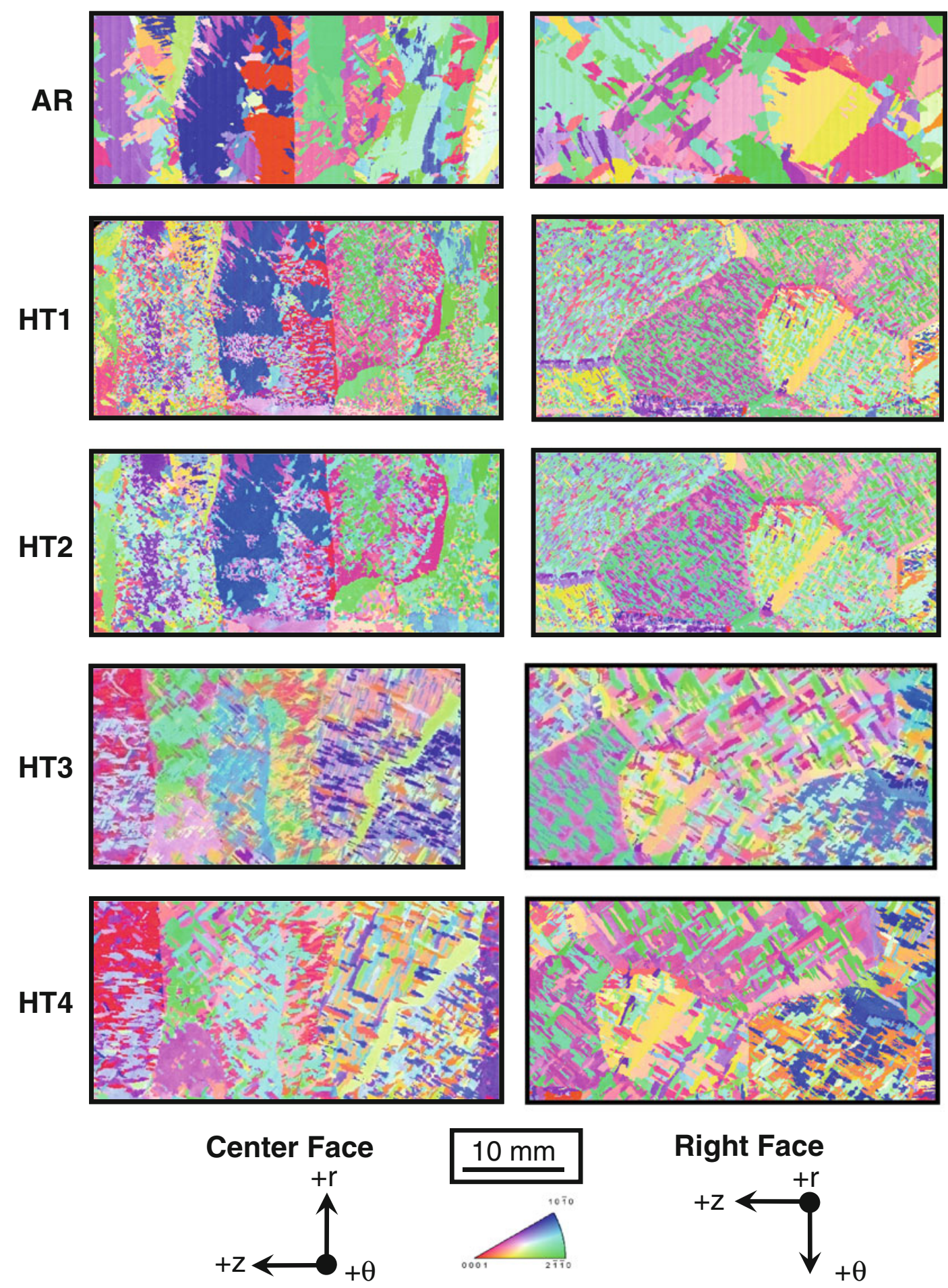

Fig. 7-Z-direction inverse pole figure maps for the alpha phase on the center and right faces of sample 2B-B-1-1 in the AR condition and after heat treatments HT1, HT2, HT3, and HT4.

Burgers relation with the same $\{110\}_{\beta}$ plane and thus gave rise to the same transformation strain.

For grain 3, variant 11 had the greatest area fraction $(\sim 0.49)$ and variant 10 the second-largest fraction $(\sim 0.24)$ in the as-received condition (Figure 8). After HT1 and HT2, the most common variant was still number 11 with an area fraction of $\sim 0.4$, but a large number of other variants with fractions of $\sim 0.10$ or less was noted. The variants found after HT3 and HT4 were similar to each other but noticeably different from those for the AR, HT1, and HT2 conditions. Specifically, variant 3 was most common ( $\sim .25$ area fraction), but variants 2,9 , and 10 each had an area fraction between approximately 0.10 and 0.20 for HT3 and HT4.

The observations for center-face grain 7 (Figure 9) were similar. The principal variant in the AR condition 

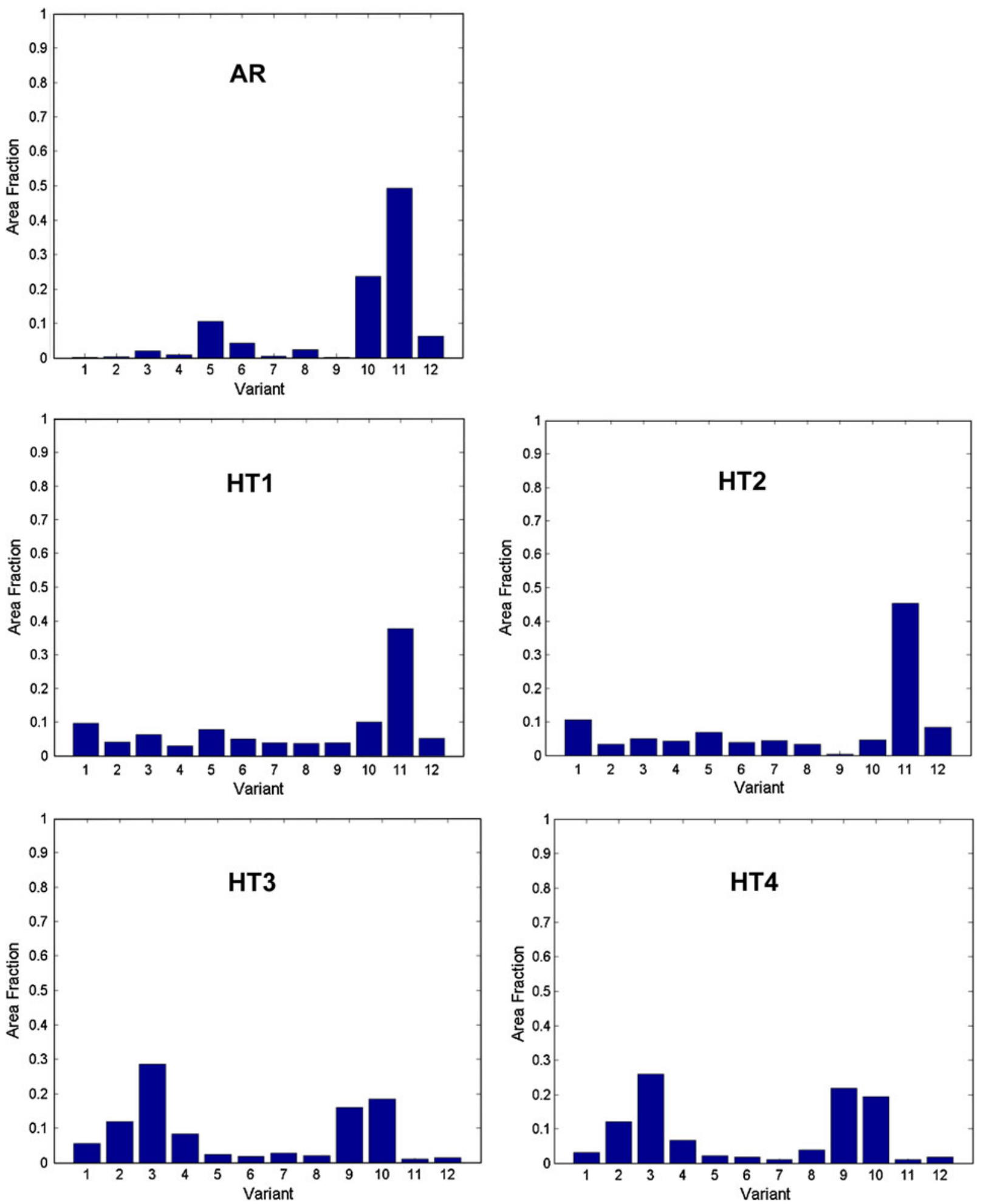

Fig. 8- Histograms of the fractions of alpha-phase variants developed in center-face grain 3 in the AR condition or after heat treatments HT1, HT2, HT3, and HT4.

was variant 11 (area fraction $\sim 0.47$ ) with substantial amounts of variant 2 (fraction $\sim 0.25$ ). The principal variant after HT1 and HT2 was also 11, but its area fraction was less $(\sim 0.35)$. In concert with this reduction, it was found that the combined area fraction of variants
1 and 2 was comparable to or slightly greater than that of variant 2 in the AR condition. Similar to the behavior for grain 3, the alpha variants after HT3 and HT4 were noticeably different from those in the other conditions. In both HT3 and HT4, variant 1 

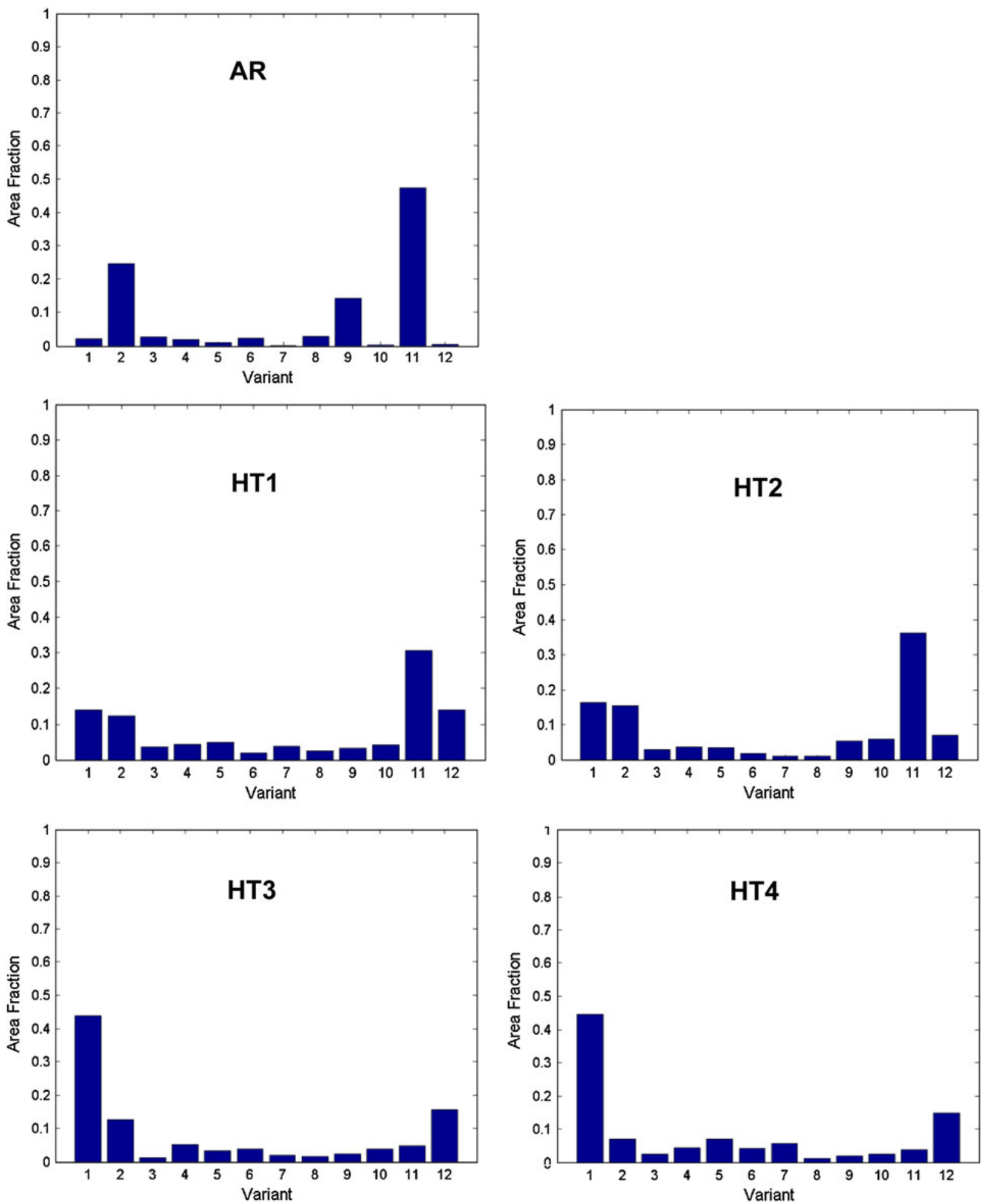

Fig. 9-Histograms of the fractions of alpha-phase variants developed in center-face grain 7 in the AR condition or after heat treatments HT1, HT2, HT3, and HT4.

predominated by a large margin, and variant 12 was second most common.

Further confirmation of a significant memory effect was deduced from the observations for HT5, which used a cooling rate $\left(15 \mathrm{~K} / \mathrm{min}\left[15^{\circ} \mathrm{C} / \mathrm{min}\right]\right)$ identical to that for HT1 and HT2. Histograms of the area fractions of alpha-phase variants in two different beta grains (6 and 7, Figure 5(a)) on the right face of the ingot sample 2B-B1-1 following the five heat treatments are shown in Figures 10 and 11. For grain 6 (Figure 10), alpha-phase variants 3 and 10 were most prominent for heat treatments HT1, HT2, and HT5. Similarly, in grain 7 

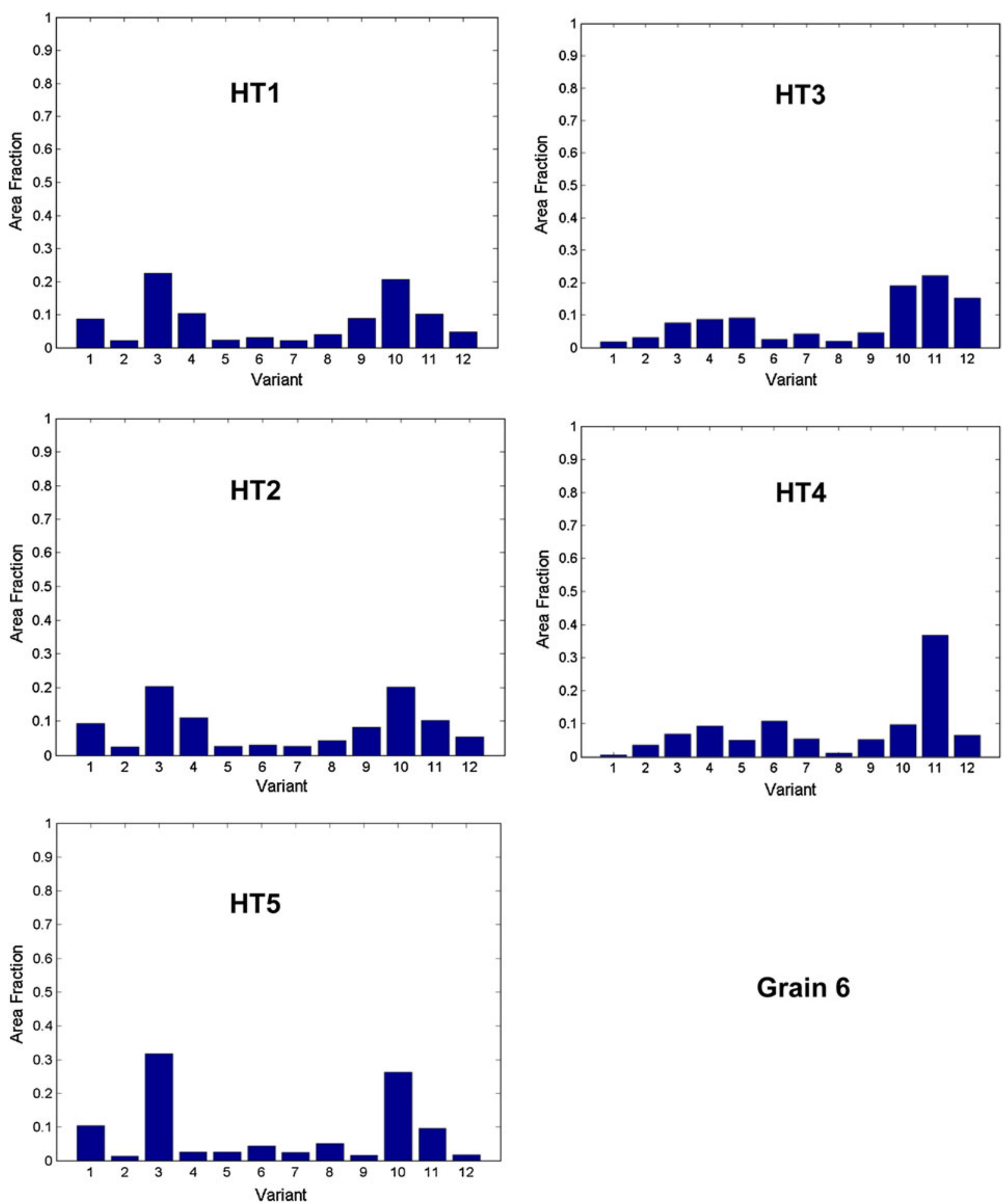

Grain 6

Fig. 10-Histograms showing the fractions of alpha-phase variants developed in right-face grain 6 after heat treatments HT1, HT2, HT3, HT4, and HT5.

(Figure 11), alpha-phase variants 3, 4, and 11 were most prominent for HT1, HT2, and HT5. Figures 10 and 11 also reveal that variant selection after HT3 and HT4, which used a slower cooling rate $5 \mathrm{~K} / \mathrm{min}\left(5^{\circ} \mathrm{C} / \mathrm{min}\right)$, was similar for each specific grain but was significantly different from that observed after HT1, HT2, and HT5. Because the five heat treatments were performed sequentially on the same ingot sample, it may be concluded that cooling rate per se has a significant effect on alpha-variant selection and that the effect is reversible.

\section{Transformation Strain}

Calculations of the deformation associated with the beta-to-alpha transformation showed that the strains 

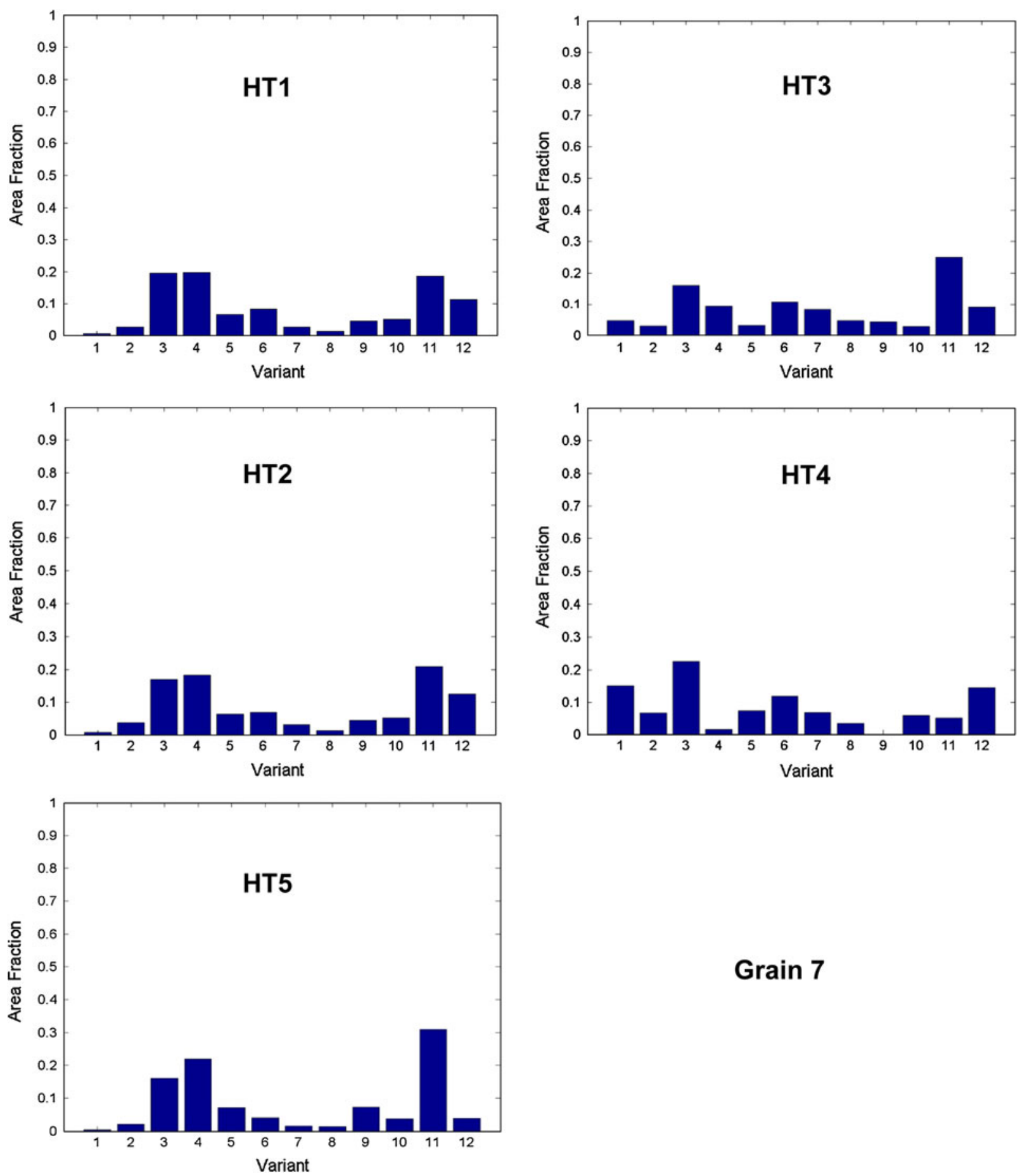

Grain 7

Fig. 11-Histograms showing the fraction of alpha-phase variants developed in right-face grain 7 after heat treatments HT1, HT2, HT3, HT4, and HT5.

varied from one beta grain to another, but the average (net) strain for all of the grains in the test samples was relatively small.

The strain components in the ingot-axis coordinate system for each specific beta grain were determined by weighting the individual variant transformation strains by the measured area/volume fractions for that grain. These strains are summarized in Tables II through V for the AR, HT2, and HT4 conditions.
The results for as-received sample 2B-B-1-1 (Table II) and as-received sample 2B-B-1-2 (Table III) are typical of the entire set of data. They revealed that the magnitude of the maximum strain components in each grain were approximately \pm 0.02 to 0.07 ; i.e., they were of the same order as the normal strain associated with the formation of each individual variant $(\sim \pm 0.10)$. The magnitudes of these strains were also much greater than that which would be expected if there were no 
Table II. Average Transformation Strains in Individual Grains and Overall Aggregate in As-Received Ti-6Al-4V Ingot Sample 2B-B-1-1AR

\begin{tabular}{|c|c|c|c|c|c|c|c|}
\hline Face & Grain ID & $\varepsilon_{r r}$ & $\varepsilon_{r z}$ & $\varepsilon_{r \theta}$ & $\varepsilon_{z z}$ & $\varepsilon_{z \theta}$ & $\varepsilon_{\theta \theta}$ \\
\hline Center & 1 & -0.0454 & 0.0043 & 0.0008 & 0.0209 & 0.0207 & 0.0086 \\
\hline Center & 2 & 0.0372 & -0.0043 & 0.0193 & 0.0003 & -0.0323 & -0.0534 \\
\hline Center & 3 & -0.0736 & -0.0123 & 0.0128 & 0.0456 & -0.0064 & 0.0121 \\
\hline Center & 4 & -0.0263 & -0.0001 & -0.0073 & -0.0295 & -0.0074 & 0.0398 \\
\hline Center & 5 & -0.0195 & 0.0104 & 0.0010 & 0.0157 & -0.0105 & -0.0122 \\
\hline Center & 6 & -0.0417 & -0.0100 & 0.0037 & 0.0402 & -0.0014 & -0.0144 \\
\hline Center & 7 & -0.0492 & 0.0047 & -0.011 & -0.0078 & 0.0042 & 0.0412 \\
\hline Center & 9 & -0.0246 & 0.0150 & 0.0047 & 0.0377 & 0.0115 & -0.0290 \\
\hline Center & 10 & 0.0132 & 0.0087 & 0.0335 & -0.0984 & -0.0086 & 0.0693 \\
\hline Center & Average* & -0.0383 & 0.0005 & 0.0037 & 0.0164 & -0.0032 & 0.0060 \\
\hline Right & 1 & 0.0193 & -0.0116 & 0.0242 & -0.0525 & 0.0046 & 0.0172 \\
\hline Right & 3 & -0.0259 & -0.0028 & -0.0054 & 0.0155 & -0.0040 & -0.0056 \\
\hline Right & 6 & 0.0061 & 0.0094 & 0.0015 & -0.0079 & 0.0053 & -0.0141 \\
\hline Right & 7 & 0.0065 & 0.0219 & -0.0209 & 0.0102 & -0.0366 & -0.0326 \\
\hline Right & 8 & -0.0300 & 0.0124 & -0.0024 & 0.0214 & -0.0259 & -0.0074 \\
\hline \multirow[t]{2}{*}{ Right } & Average* & -0.0056 & 0.0003 & 0.0038 & -0.0080 & -0.0035 & -0.0024 \\
\hline & Random $^{\dagger}$ & -0.0053 & 0.0000 & 0.0000 & -0.0053 & 0.0000 & -0.0053 \\
\hline
\end{tabular}

*Overall average weighted by the area fraction of each grain on the specific face of the sample.

${ }^{\dagger}$ Hypothetical case with no preferential variant selection.

Table III. Average Transformation Strains in Individual Grains and Overall Aggregate in As-Received Ti-6Al-4V Ingot, 2B-B-1-2AR

\begin{tabular}{llcrrrr}
\hline Face & Grain ID & \multicolumn{1}{c}{$\varepsilon_{r r}$} & \multicolumn{1}{c}{$\varepsilon_{r z}$} & $\varepsilon_{r \theta}$ & \multicolumn{1}{c}{$\varepsilon_{z z}$} & $\varepsilon_{z \theta}$ \\
\hline Right & 2AR-1 & 0.0148 & -0.0192 & 0.0155 & -0.0329 & -0.0123 \\
Right & 2AR-2 & -0.0061 & -0.0036 & 0.0134 & 0.0012 & 0.0118 \\
Right & 2AR-3 & -0.0062 & 0.0034 & 0.0204 & -0.0231 & -0.0367 \\
Right & 2AR-4 & -0.0254 & -0.0055 & 0.0063 & 0.0032 & 0.0037 \\
Right & 2AR-5 & 0.0310 & 0.0228 & -0.0183 & 0.0324 & -0.0103 \\
Right & 2AR-6 & 0.0160 & 0.0035 & -0.0270 & -0.0408 & 0.0134 \\
Right & 2AR-7 & 0.0066 & 0.0055 & 0.0015 & -0.0219 & -0.0063 \\
Right & Average* & 0.0044 & 0.0004 & -0.0005 & -0.0202 & -0.0002 \\
\hline
\end{tabular}

*Overall average weighted by the area fraction of each grain on the right face of the sample.

preferential variant selection. Specifically, as shown in Table II, if all 12 variants were produced equally in a given grain, the net (average) transformation strain induced (in the cubic-crystal axis system) would be $\varepsilon_{11}=\varepsilon_{22}=\varepsilon_{33}=-0.0053$ and $\varepsilon_{12}=\varepsilon_{23}=\varepsilon_{31}=0$ for the individual variant strains given in Section II-C.

Even though each individual grain underwent a strain in excess of that associated with the ideal case of no variant selection, the average strain over the aggregate of beta grains on a given face (weighted by the specific grain area fractions on that face) was considerably smaller. For the as-received condition of sample 2B-B-1-1, for example, the magnitude of each of the average aggregate strain components, except $\varepsilon_{\mathrm{rr}}$, was less than 0.02 (Table II); $\varepsilon_{\mathrm{rr}}$ was estimated to be either -0.0383 (using center-face data) or -0.0056 (using right-face data). Similarly, for sample 2B-B-1-2 (Table III), the magnitude of the average of each of the strain components was less than 0.02 for the right-face grains.

Tables IV and V show the average transformation strains in individual grains and the overall average aggregate strains for sample 2B-B-1-1 following HT2 and HT4, respectively. In both cases, the area-weighted average strains for ensemble represented on each face were considerably smaller than the strains for each individual grain.

The relatively small overall strains induced in the aggregate suggest a long-range, multiple-grain interaction during beta-phase decomposition. Several hypotheses may be proposed for this interaction. The simplest is based on variant selection, which is a function of the orientation of each beta-grain orientation per se and its interaction with a so-called homogeneous effective medium. If this were the case, the average transformation strain experienced by beta grains with the same orientation would be the same. Because the test samples contained a $\langle 100\rangle_{\beta}$ fiber texture, this hypothesis was relatively easy to assess by examining beta grains whose rotation about the fiber (radial) axis was identical. Grains 1, 7 on the center face and 3, 6, 14 and 8, 10 on the right face of sample $2 \mathrm{~B}-\mathrm{B}-1-1$ met this requirement (Table I). The calculations summarized in Table II for the as-received condition showed a similarity for some strain components and large differences for others, however.

A second hypothesis for the observation of small overall aggregate strains would invoke local neighborhood effects on variant selection, such as those 
Table IV. Average Transformation Strains in Individual Grains and Overall Aggregate in Ti-6Al-4V Ingot Sample 2B-B-1-1 after HT2

\begin{tabular}{|c|c|c|c|c|c|c|c|}
\hline Face & Grain ID & $\varepsilon_{r r}$ & $\varepsilon_{r z}$ & $\varepsilon_{r \theta}$ & $\varepsilon_{z z}$ & $\varepsilon_{z \theta}$ & $\varepsilon_{\theta \theta}$ \\
\hline Center & 1 & -0.0145 & -0.0015 & -0.0133 & -0.0187 & 0.0234 & 0.0172 \\
\hline Center & 2 & 0.0286 & 0.0018 & 0.0129 & -0.0074 & -0.0095 & -0.0372 \\
\hline Center & 3 & -0.0417 & -0.0150 & -0.0013 & 0.0333 & 0.0055 & -0.0075 \\
\hline Center & 4 & -0.0194 & -0.0020 & -0.0123 & -0.0343 & 0.0056 & 0.0378 \\
\hline Center & 5 & -0.0030 & 0.0115 & -0.0016 & 0.0045 & 0.0089 & -0.0174 \\
\hline Center & 6 & -0.0563 & -0.0301 & -0.0140 & 0.0048 & -0.0005 & 0.0356 \\
\hline Center & 7 & -0.0356 & -0.0001 & -0.0177 & -0.0165 & 0.0022 & 0.0362 \\
\hline Center & 10 & -0.0324 & -0.0027 & -0.0145 & -0.0094 & -0.0114 & 0.0258 \\
\hline Center & Average* & -0.0216 & -0.0032 & -0.0068 & -0.0007 & 0.0090 & 0.0064 \\
\hline Right & 1 & 0.0162 & -0.0224 & -0.0133 & -0.0286 & 0.0077 & -0.0036 \\
\hline Right & 3 & 0.0268 & 0.0003 & -0.0133 & -0.0266 & -0.0022 & -0.0162 \\
\hline Right & 6 & 0.0276 & -0.0039 & 0.0053 & -0.0206 & 0.0011 & -0.0229 \\
\hline Right & 7 & 0.0231 & 0.0107 & 0.0025 & -0.0199 & -0.0074 & -0.0191 \\
\hline Right & 8 & 0.0325 & 0.0102 & 0.0107 & -0.0329 & 0.0046 & -0.0156 \\
\hline Right & Average* & 0.0227 & -0.0035 & -0.0044 & -0.0247 & 0.0014 & -0.0139 \\
\hline
\end{tabular}

*Overall average weighted by the area fraction of each grain on the specific face of the sample.

Table V. Average Transformation Strains in Individual Grains and Overall Aggregate in Ti-6Al-4V Ingot 2B-B-1-1 after HT4

\begin{tabular}{|c|c|c|c|c|c|c|c|}
\hline Face & Grain ID & $\varepsilon_{r r}$ & $\varepsilon_{r z}$ & $\varepsilon_{r \theta}$ & $\varepsilon_{z z}$ & $\varepsilon_{z \theta}$ & $\varepsilon_{\theta \theta}$ \\
\hline Center & 3 & -0.0227 & 0.0049 & 0.0025 & -0.0176 & 0.0276 & 0.0243 \\
\hline Center & 4 & -0.0041 & -0.0016 & -0.0049 & -0.0304 & -0.0028 & 0.0186 \\
\hline Center & 5 & -0.0078 & -0.0003 & -0.0030 & -0.0407 & -0.0039 & 0.0325 \\
\hline Center & 6 & -0.0165 & -0.0131 & -0.0076 & -0.0007 & 0.0082 & 0.0012 \\
\hline Center & 7 & 0.0143 & 0.0043 & -0.0204 & -0.0436 & -0.0091 & 0.0133 \\
\hline Center & 9 & -0.0111 & 0.0022 & -0.0125 & -0.0089 & -0.0068 & 0.0041 \\
\hline Center & 10 & -0.0467 & 0.0435 & -0.0112 & -0.0232 & -0.0109 & 0.0539 \\
\hline Center & Average* & -0.0105 & 0.0010 & -0.0041 & -0.0234 & 0.0018 & 0.0180 \\
\hline Right & 1 & -0.0017 & 0.0055 & 0.0058 & -0.0078 & -0.0099 & -0.0065 \\
\hline Right & 3 & -0.0103 & -0.0014 & -0.0027 & -0.0053 & -0.0020 & -0.0003 \\
\hline Right & 6 & 0.0017 & 0.0004 & 0.0040 & -0.0144 & 0.0024 & -0.0033 \\
\hline Right & 7 & 0.0120 & 0.0089 & -0.0098 & 0.0036 & -0.0242 & -0.0316 \\
\hline Right & 8 & 0.0084 & 0.0152 & -0.0084 & 0.0044 & -0.0144 & -0.0288 \\
\hline Right & Average* & 0.0032 & 0.0047 & 0.0000 & -0.0168 & -0.0008 & -0.0063 \\
\hline
\end{tabular}

*Overall average weighted by the area fraction of each grain on the specific face of the sample.

suggested in References 20 and 22. For example, Bhattacharyya et al. ${ }^{[20]}$ suggested that the critical nucleus size is decreased at prior beta grain boundaries that share common $\langle 110\rangle$ directions. Thus, the probability for the occurrence of such a grain boundary in both randomly oriented and $\langle 100\rangle$-fiber-textured material was determined numerically in the current work; the latter texture is an idealized approximation for the current Ti-6Al-4V ingot whose coarse grain size precluded EBSD orientation measurements for a large number of grains. Specifically, Euler angles were selected randomly from a list of discrete orientations representing either a uniformly distributed ODF or a $\langle 100\rangle$ fiber. The angles between all $\langle 110\rangle$ directions in the two orientations were calculated. For an angular tolerance of $5 \mathrm{deg}$, it was found that such a boundary would be expected with a frequency of only 4.5 pct in a random-oriented material. Because of the higher degree of symmetry, the probability increased to $\sim 12$ pct for the case of an axisymmetric $\langle 100\rangle$ fiber with a 7.5 deg half width. The standard deviation for both sets of calcula- tions was less than $0.5 \mathrm{deg}$. Because of the large grain size and low probability of $\langle 110\rangle$ alignment, these calculations thus suggest that grain-boundary-influenced variant selection is not a strong contributor to the overall alpha-phase transformation texture observed in the production-scale ingot after solidification or subsequent supersolvus heat treatment.

The third possibility to explain large-scale strain accommodation, or the one most strongly supported by the experimental data (Tables II through V), is the occurrence of sympathetic nucleation. According to this mechanism, the internal stress state at each location within the ingot influences the next variant that is selected during nucleation to minimize the total elastic strain energy of the system. Physically, this occurs via heterogeneous nucleation from the lower energy broad face of an existing alpha lath. This mechanism is favored for faster cooling rates where "packets" of small colonies or individual alpha laths self-accommodate via elastic interactions and plastic strain accommodation via dislocation glide, ${ }^{[39]}$ but also it can be observed for 
slower cooling rates as evident by the repetitive geometric patterns in Figure 7, for example.

Strictly speaking, the transformation strains for the bcc to hep transformation calculated in the current work (Tables II through V) apply only at the early stages of nucleation inasmuch as they are based on the assumption of a fully coherent interface. As alpha laths grow and coherency is lost, dislocation-accommodated structural ledges are formed that localize strain at the interface. Nevertheless, weighting the transformation strains by the area fraction of each variant is appropriate because the ratios of the transformation strains remain approximately the same throughout all stages of growth. If they changed considerably from that at nucleation and during the early stages of growth, the alpha phase would not take lath-like morphology. ${ }^{[40]}$

\section{SUMMARY AND CONCLUSIONS}

Variant selection during cooling after beta annealing of coarse-beta-grain Ti-6Al-4V ingot samples was investigated. The following conclusions were drawn:

1. Repeated heat treatment above the beta-transus temperature leads to minimal beta grain growth for coarse starting grain sizes such as are found in production-scale ingots.

2. The selection of the alpha variants within each beta grain exhibits a memory effect. The exact fractions of the variants depend on the cooling rate after beta annealing.

3. Calculation of the strains associated with the betato-alpha transformation with each beta grain underscore the nonrandom nature of the variant-selection process. The overall (average) strain developed within an entire aggregate of grains is much smaller than the transformation strain for a single variant, thus suggesting an interaction spanning multiple grains whose source is yet to be determined.

\section{ACKNOWLEDGMENTS}

This work was conducted as part of the in-house research of the Metals Branch of the Air Force Research Laboratory's Materials and Manufacturing Directorate. The support and encouragement of the Laboratory management is gratefully acknowledged. Two authors were supported under Air Force contracts FA8650-04-D-5235 (G.A.S.) and FA8650-09-2-5800 (K.T.K.). Technical discussions with M.G. Glavicic (Rolls-Royce, Indianapolis, IN) are also greatly appreciated.

\section{REFERENCES}

1. F. Larson and A. Zarkades: "Properties of Textured Titanium Alloys," Report MCIC-74-20, Metals and Ceramics Information Center, Battelle Memorial Institute, Columbus, OH, 1974.

2. G. Luetjering and M. Peters: "Mechanical Properties of a Titanium Blading Alloy," Report EPRI CS-2933, Electric Power Research Institute, Palo Alto, CA, 1983.

3. G. Luetjering: Mater. Sci. Eng. A, 1998, vol. A243, pp. 32-45.
4. U.F. Kocks, C.N. Tome, and H.R. Wenk: Texture and Anisotropy, Cambridge University Press, Cambridge, U.K., 1998.

5. S.L. Semiatin, M.G. Glavicic, S.V. Shevchenko, O.M. Ivasishin, Y.B. Chun, and S.K. Hwang: in ASM Handbook, Vol. 22A: Fundamentals of Modeling for Metals processing, D.U. Furrer and S.L. Semiatin, eds., in ASM International, Materials Park, OH, 2009, pp. 536-52.

6. M. Peters and G. Luetjering: in Titanium '80: Science and Technology, H. Kimura and O. Izumi, eds., TMS, Warrendale, PA, 1980, pp. 925-35.

7. J.C. Williams and E.A. Starke, Jr.: in Deformation, Processing, and Structure, G. Krauss, ed., ASM International, Materials Park, OH, 1984, pp. 279-354.

8. Y.B. Chun, S.H. Yu, S.L. Semiatin, and S.K. Hwang: Mater. Sci. Eng. A, 2005, vol. A398, pp. 209-19.

9. Y.B. Chun, S.L. Semiatin, and S.K. Hwang: Acta Mater., 2006, vol. 54, pp. 3673-89.

10. O.M. Ivasishin, S.V. Shevchenko, N.L. Vasiliev, and S.L. Semiatin: Acta Mater., 2003, vol. 51, pp. 1019-34.

11. O.M. Ivasishin, S.V. Shevchenko, N.L. Vasiliev, and S.L. Semiatin: Mater. Sci. Eng. A, 2006, vol. A433, pp. 216-32.

12. W.G. Burgers: Physica, 1934, vol. 1, pp. 561-86.

13. H. Moustahfid, N. Gey, M. Humbert, and M.J. Philippe: Metall. Mater. Trans. A, 1997, vol. 28A, pp. 51-59.

14. S.L. Semiatin, P.N. Fagin, M.G. Glavicic, I.M. Sukonnik, and O.M. Ivasishin: Mater. Sci. Eng. A, 2001, vol. A299, pp. 225-34.

15. N. Gey, M. Humbert, M.J. Philippe, and Y. Combres: Mater. Sci. Eng. A, 1996, vol. A219, pp. 80-88.

16. N. Gey, M. Humbert, M.J. Philippe, and Y. Combres: Mater. Sci. Eng. A, 1997, vol. A230, pp. 68-74.

17. S.V. Divinski, V.N. Dnieprenko, and O.M. Ivasishin: Mater. Sci. Eng. A, 1998, vol. A243, pp. 201-05.

18. M. Humbert, L. Germaine, N. Gey, P. Bocher, and M. Jahazi: Mater. Sci. Eng. A, 2006, vol. A430, pp. 157-64.

19. L. Zeng and T.R. Bieler: Mater. Sci. Eng. A, 2005, vol. A392, pp. 403-14.

20. D. Bhattacharyya, G.B. Viswanathan, R. Denkenberger, D. Furrer, and H.L. Fraser: Acta Mater., 2003, vol. 51, pp. 4679-91.

21. N. Stanford and P.S. Bate: Acta Mater., 2004, vol. 52, pp. 5215-24.

22. I. Lischewski and G. Gottstein: Acta Mater., 2011, vol. 59, pp. $1530-41$.

23. A.W. Bowen: Mater. Sci. Eng., 1977, vol. 29, pp. 19-28.

24. I. Lonardelli, N. Gey, H.-R. Wenk, M. Humbert, S.C. Vogel, and L. Lutterotti: Acta Mater., 2007, vol. 55, pp. 5718-27.

25. J. Romero, M. Preuss, and J. Quinta da Fonseca: Acta Mater., 2009, vol. 57, pp. 5501-11.

26. M.R. Daymond, R.A. Holt, S. Cai, P. Mosbrucker, and S.C. Vogel: Acta Mater., 2010, vol. 58, pp. 4053-66.

27. M.G. Glavicic, P.A. Kobryn, F. Spadafora, and S.L. Semiatin: Mater. Sci. Eng. A, 2003, vol. A346, pp. 8-18.

28. A.R. Shiveley, P.A. Shade, A.L. Pilchak, J.S. Tiley, and R. Kerns: J. Microscopy, 2011, vol. 244 (2), pp. 181-86.

29. A.L. Pilchak, A.R. Shiveley, J.S. Tiley, and D.L. Ballard: J. Microscopy, 2011, vol. 244 (1), pp. 38-44.

30. M. Humbert, H. Moustahfid, F. Wagner, and M.J. Philippe: Mater. Sci. Forum, 1994, vol. 157, pp. 1225-30.

31. M. Humbert, F. Wagner, H. Moustahfid, and C. Esling: J. Appl. Cryst., 1995, vol. 28, pp. 571-76.

32. M.G. Glavicic, P.A. Kobryn, T.R. Bieler, and S.L. Semiatin: Mater. Sci. Eng. A, 2003, vol. A346, pp. 50-59.

33. M.G. Glavicic, P.A. Kobryn, T.R. Bieler, and S.L. Semiatin: Mater. Sci. Eng. A, 2003, vol. A351, pp. 258-64.

34. A.L. Pilchak and J.C. Williams: Metall. Mater. Trans. A, 2011, vol. 42A, pp. 773-94.

35. A. Kelly, G.W. Groves, and P. Kidd: Crystallography and Crystal Defects, Wiley, West Sussex, U.K., 2000.

36. C. Leyens and M. Peters: Titanium and Titanium Alloys: Fundamentals and Applications, Wiley-VCH, Weinheim, Germany, 2003.

37. J.W. Elmer, T.A. Palmer, S.S. Babu, and E.D. Specht: Mater. Sci. Eng. A, 2005, vol. A391, pp. 104-13.

38. S.L. Semiatin, J.C. Soper, and I.M. Sukonnik: Acta Metall. Mater., 1996, vol. 44, pp. 1979-86.

39. S.C. Wang, M. Aindow, and M.J. Starink: Acta Mater., 2003, vol. 51, pp. 2485-503.

40. Y. Wang, N. Ma, Q. Chen, F. Zang, S.-L. Chen, and Y.A. Chang: JOM, 2005, vol. 57 (9), pp. 32-39. 